\title{
CARACTERIZAÇÃO FARMACOGNÓSTICA DAS FOLHAS DE EUGENIA UNIFLORA L. (MYRTACEAE)
}

\section{Pharmacognostic characterization of the leaves of Eugenia uniflora L. (Myrtaceae)}

\author{
Tatiana S. Fiuza ${ }^{1}$, Maria Helena Rezende ${ }^{2}$, Simone M. T. Sabóia-Morais ${ }^{1}$, Maria Teresa F. Bara ${ }^{3}$, \\ Leonice M. F. Tresvenzol ${ }^{3}$, José Realino de Paula ${ }^{3^{*}}$. \\ ${ }^{1}$ Laboratório de Biologia Celular, ICB/ UFG, C.P.131, Goiânia-GO, 74001-970, Brasil. \\ ${ }^{2}$ Laboratório de Anatomia Vegetal, ICB/ UFG, C.P.131, Goiânia-GO, 74001-970, Brasil. \\ ${ }^{3}$ Laboratório de Pesquisa em Produtos Naturais, FF/ UFG, C.P. 131, Goiânia-GO, 74001-970, Brasil.
}

*Autor para correspondência: pjrpaula@gmail.com

Recebido em 05/08/2008 - Aceito em 11/09/2008

RESUMO: Eugenia uniflora L. é utilizada popularmente como anti-hipertensivo, diurético, adstringente, entre outros. Objetivou-se estudar a anatomia das folhas e caule jovem de E. uniflora e fazer o estudo farmacognóstico para a identificação e controle de qualidade da matéria prima vegetal. O material botânico foi coletado em Goiânia, Goiás, dessecado e pulverizado. Determinaram-se os teores de umidade, cinzas totais e insolúveis em ácido. Nas análises microscópicas utilizaram-se as colorações: azul de Alcian/safranina 9:1, Steinmetz, Sudan III, cloreto férrico, lugol, safrablau. O material pulverizado foi utilizado para a triagem fitoquímica, obtenção do extrato etanólico bruto e posteriormente as frações. Por cromatografia em camada delgada (CCD) avaliou-se o perfil cromatográfico das frações. Observaram-se na epiderme da face adaxial da folha, células com paredes anticlinais espessadas, sinuosas e na face abaxial, a presença de estômatos predominantemente anomocíticos. O pecíolo apresentou forma côncava-convexa com parênquima cortical contendo cristais em forma de drusa. Verificou-se no caule jovem em secção transversal forma oval, colênquima com uma a duas camadas de células. Na triagem fitoquímica evidenciou-se a presença de taninos, esteróides, triterpenos, heterosídeos antraquinônicos, saponínicos e flavonóides e em CCD, a presença de flavonóides, taninos e terpenos. Os resultados obtidos podem ajudar na identificação morfo-anatômica de E. uniflora, assim como nos parâmetros de controle de qualidade para a identificação da matéria-prima.

PALAVRAS-CHAVE: fitoterapia, plantas medicinais.

ABSTRACT: Eugenia uniflora $L$ is popularly used, among other things, as an antihypertertensive, diuretic and adstringent drug. The purpose of this work is to study the leaf and young stem anatomy of $E$. uniflora and perform a pharmacognostic study with a view to the identification and quality control of vegetal raw materials. The botanical material was collected in Goiânia, Goiás, desiccated and pulverized. The humidity, total ash and acid-insoluble contents were determined. The following stains were used for the microscopic analyses: Alcian-safranin blue 9:1, Steinmetz, Sudan III, ferric chloride, lugol, safrablau. The pulverized material was used for the phytochemical screening, obtention of the crude ethanol extract and subsequently its fractions. The chromatographic profile of the fractions was evaluated by Thin Layer Chromatography (TLC). Cells with thickened wavy anticlinal walls were noted on the epidermis of the adaxial leaf surface while the presence of predominantly anomocytic stomates was noted on the abaxial surface. The petiole presented a concave-convex shape with cortical parenchyma containing druse shaped crystals. Cross section of the young stem revealed an oval shape, colenchyma with one or two cell layers. The phytochemical screening evidenced the presence of tannins, steroids, triterpenes heterosides, anthraquinones, saponins and flavonoids and TLC indicated the presence of flavonoids, tannins and terpenes. Results shown may help the identification of the $E$. uniflora morphoanatomy as well as the quality control parameters for the identification of the plant drug

KEY WORDS: phytotherapy, medicinal plants. 
Fiuza, T. S. et al./Revista Eletrônica de Farmácia Vol 5(2), 21-31, 2008.

O gênero Eugenia L. é um dos maiores da família Myrtaceae, com mais de 500 espécies, das quais cerca de 400 encontram-se no Brasil e assumem destaque especial por serem utilizadas como plantas medicinais. Dentro deste gênero tem-se Eugenia uniflora L. (pitangueira), que se apresenta como um arbusto ou árvore semidecídua, de 4 a $10 \mathrm{~m}$ de altura, copa estreita, de tronco liso de cor pardo clara. As folhas são simples, cartáceas, de 3 a $7 \mathrm{~cm}$ de comprimento, com aroma característico. As flores são de cor branca, solitárias ou em grupos de 2-3 nas axilas e nas extremidades dos ramos. Os frutos são do tipo drupa, globosos e sulcados, brilhantes e de cor vermelha, amarela ou preta, com polpa carnosa e agridoce, contendo 1 a 2 sementes (LORENZI e MATOS, 2002)

E. uniflora L. é uma espécie que cresce na Argentina, Uruguai, Paraguai e Brasil (PEPATO et al., 2001). É cultivada na América Central, Antilhas, Flórida, Califórnia, Havaí, China Meridional, Ceilão, Argélia, Tunísia, Sul da França, face sua grande capacidade de adaptação. No Brasil ocorre desde o Estado de Minas Gerais até o Rio Grande do Sul (SANCHOTENE, 1985).

E. uniflora foi introduzida na medicina empírica pelos índios Guaranis no século XV (ALONSO, 1998) e é utilizada como fármaco anti-hipertensivo, diurético (CONSOLINI e SARUBBIO, 2002), adstringente (BANDONI et al., 1972), antipirético e para o tratamento de desordens digestivas (ALICE et al., 1991). Na Ilha da Madeira as folhas de E. uniflora são utilizadas no tratamento de bronquites, gripes e problemas intestinais e na Nigéria como um febrífugo (CONSOLINI e SARUBBIO, 2002).

Ensaios farmacológicos realizados com os extratos das folhas da $E$. uniflora permitiram evidenciar atividade inibitória da enzima xantina-oxidase por ação dos flavonóides (SCHMEDA-HIRSCHMANN et al., 1987), diminuição da pressão sanguínea mediado pela vasodilatação direta e uma fraca ação diurética que pode estar relacionada com o aumento do fluxo sanguíneo renal (CONSOLINI et al., 1999), atividade antibacteriana contra alguns germes patogênicos (FADEY e AKPAN, 1989), atividade moderada tanto para Staphylococcus aureus quanto para Escherichia coli e atividade contra algumas leveduras (HOLETZ et al., 2002).

Segundo Schapoval et al. (1994) as folhas da E. uniflora são ricas em óleos essenciais contendo citronelol, geraniol, cineol e sesquiterpenos os quais têm demonstrado possuir atividade antimicrobiana. Estes autores observaram que a infusão das suas folhas produziu um aumento significativo no tempo de sono induzido pelo pentobarbital e eles correlacionaram esses achados com a composição química, especialmente monoterpenos os quais podem interferir com a distribuição do pentobarbital nos tecidos.

O presente trabalho objetivou estudar a anatomia das folhas e caule jovem da $E$. uniflora coletadas em Goiânia, Goiás, assim como fazer um estudo farmacognóstico de suas folhas visando parâmetros para o controle de qualidade da matéria-prima vegetal obtida desta espécie.

\section{MATERIAL E MÉTODOS}

\section{Material botânico}

O material botânico constituído de folhas e caule jovem da Eugenia uniflora L. foi coletado no município de Goiânia, Goiás ( $16^{\circ} 36^{\prime} 15,1^{\prime}$ S e $49^{\circ} 1^{\prime}$ ' 0,70" W, a $778 \mathrm{~m}$ de altitude) no período de fevereiro a abril de 2005 , sendo identificado pelo Prof. Dr. José Realino de Paula, da Universidade Federal de Goiás, e as exsicatas depositadas no herbário desta instituição, sob registro UFG/29859.

As folhas foram dessecadas em estufa com circulação de ar a $40^{\circ} \mathrm{C}$. Após secas as folhas foram moídas em um moinho de facas.

\section{Preparação do material botânico para análise microscópica}

Para o estudo microscópico de E. uniflora L. foram utilizados fragmentos da nervura principal, da região intercostal e bordo (apical, mediano e basal) da lâmina foliar; pecíolo e caule do segundo entrenó. As amostras foram fixadas em FPA 70 por três dias e posteriormente conservadas em etanol a $70 \%$. Posteriormente foram feitos cortes paradérmicos das faces adaxial e abaxial e cortes transversais à mão livre. Os cortes foram submetidos ao processo de dupla coloração com azul de Alcian/safranina 9:1(BUKATSCH, 1972 apud KRAUS e ARDUIN, 1997) e às reações histoquímicas com os reagentes de Steinmetz (COSTA, 2001), Sudan III (SASS, 1951), cloreto férrico (JOHANSEN, 1940) e lugol (JOHANSEN, 1940). As lâminas permanentes foram confeccionadas empregando o reagente safrablau (KRAUS e ARDUIN, 1997). A análise microscópica do pó foi feita empregando-se o reagente de Steinmetz (COSTA, 2001)

O registro fotográfico das estruturas anatômicas foi realizado em fotomicroscópio (ZEISS-AXIOSKOP), utilizando filme Kodacolor, ASA 100.

\section{Testes de pureza}

A partir do material botânico pulverizado, foram determinados em triplicata, os teores de cinzas totais e insolúveis em ácido, e o teor de umidade. Os ensaios para a determinação desses parâmetros de qualidade foram realizados conforme a Farmacopéia Brasileira IV (1988). 
Fiuza, T. S. et al./Revista Eletrônica de Farmácia Vol 5(2), 21-31, 2008.

\section{Triagem fitoquímica}

A amostra coletada foi submetida à triagem fitoquímica, sendo realizadas as pesquisas de alcalóides, amido, cumarinas, heterosídeos antraquinônicos, esteróides, triterpenos, heterosídeos digitálicos, heterosídeos flavonóides, heterosídeos saponínicos e taninos, segundo metodologias adaptadas de Costa (2001).

\section{Obtenção do extrato etanólico, frações e perfil cromatográfico em cromatografia de camada delgada (CCD).}

O pó das folhas de E. uniflora foi macerado em etanol a 95\% na proporção de 1:3 à temperatura ambiente, com agitação ocasional por $72 \mathrm{~h}$, seguido por uma filtração. $\mathrm{O}$ extrato obtido foi concentrado em rotaevaporador à temperatura de $40^{\circ} \mathrm{C}$ e o resíduo vegetal extraído por mais duas vezes de maneira análoga, obtendo assim o extrato etanólico bruto.

Para obtenção das frações, o extrato bruto foi dissolvido em metanol, no qual foi adicionada água destilada, até obtenção de uma solução $\mathrm{MeOH} / \mathrm{H}_{2} \mathrm{O}$ 7:3. A solução resultante foi extraída, sucessivamente, três vezes com hexano, clorofórmio e acetato de etila (FERRI, 1996). As frações hexânica, clorofórmica e acetato de etila foram concentradas em rotaevaporador em temperatura $\leq 40^{\circ} \mathrm{C}$.

Para as análises cromatográficas, as frações hexânica, clorofórmica e acetato de etila foram redissolvidas em etanol PA e aplicadas na cromatofolha de alumínio contendo silicagel 60 F254 (MERCK). Como fase móvel foi utilizada as seguintes misturas de solventes: acetato de etila/ácido fórmico/água (90:5:5) (análise de taninos condensados - recomendado pela Farmacopéia Brasileira IV, 2003), acetona/tolueno/ácido fórmico (3:3:1) (análise de taninos condensados e hidrolizáveis, flavonóides, terpenos e saponinas), acetato de etila/ácido fórmico/ácido acético glacial/água (100:11:11:27) (análise de flavonóides), acetato de etila/metanol/água (100:13,5:10) (análise de antraquinonas) e clorofórmio/ácido acético glacial/metanol/água (64:32:12:8) (análise de saponinas) (Wagner \& Bladt 2001). Para a revelação dos cromatogramas utilizou-se $\mathrm{FeCl}_{3} / \mathrm{HCl}$ (taninos condensados e hidrolisáveis e flavonóides), vanilina/ $\mathrm{H}_{2} \mathrm{SO}_{4}$ (terpenos, taninos condensados e hidrolizáveis, flavonóides e saponinas), $\mathrm{KOH}$ a $10 \%$ (antraquinonas, antronas, antrol e cumarinas), NP 1\% (ácido difenilbórico $1 \%$ em metanol)/PEG (polietilenoglicol) 4000 a 5\% em etanol (flavonóides, aloína), UV (365 nm) (lignanas). Após aplicação dos reveladores, as cromatoplacas foram observadas na luz visível e UV (254 e $365 \mathrm{~nm}$ ) e analisadas de acordo com descrições de Wagner \& Bladt (2001).

\section{Doseamento de fenóis totais, taninos e flavonóides}

O doseamento de fenóis totais e taninos foi realizado pelo método de Hagerman \& Butler (1978), e flavonóides totais pela metodologia descrita para a Pitangueira na Farmacopéia Brasileira IV (2003). Os doseamentos foram realizados em triplicata.

\section{RESULTADOS}

\section{Descrição microscópica}

As folhas de E. uniflora são hipoestomáticas com estômatos predominantemente anomocíticos. A epiderme da face adaxial, em secção paradérmica, apresenta células de vários tamanhos com paredes anticlinais espessadas e onduladas (Figura 1A). Na epiderme da face abaxial, as células são de tamanhos variados com paredes anticlinais espessadas e sinuosas. Observam-se cavidades secretoras circundadas radialmente por duas ou, raramente, por um conjunto de até seis células epidérmicas (Figuras 1B e 1C). 
Fiuza, T. S. et al./Revista Eletrônica de Farmácia Vol 5(2), 21-31, 2008.
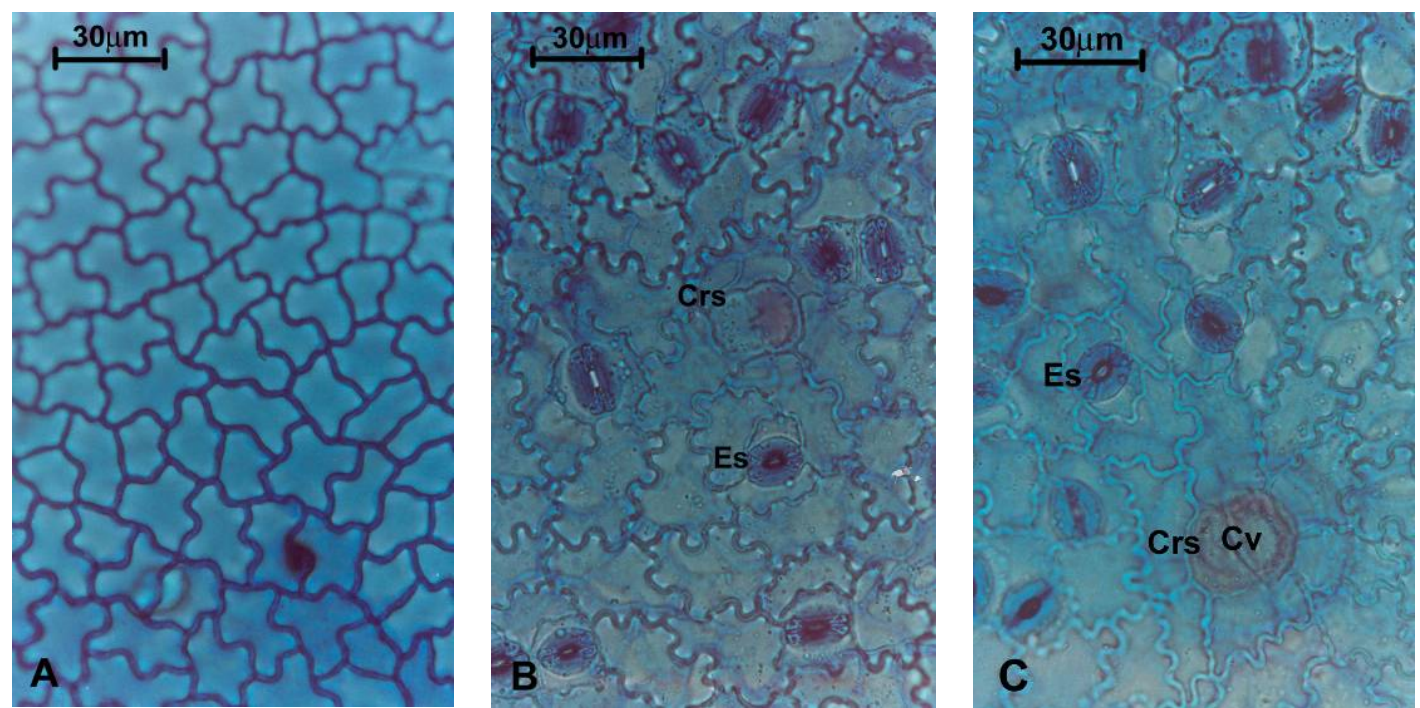

Figura 1. Seç̧ões paradérmicas da lâmina foliar de Eugenia uniflora L. em coloração com azul de Alcian/Safranina. A - Epiderme adaxial. B e C - Epiderme abaxial. Crs = células que circundam radialmente a cavidade secretora; $\mathbf{C v}$ = cavidade secretora; Es = estômato.

A lâmina foliar de E. uniflora, em secção transversal, apresenta epiderme unisseriada em ambas as faces. $\mathrm{Na}$ face adaxial observa-se cutícula espessa (Figura 2C), mesofilo dorsiventral com parênquima paliçádico unisseriado, parênquima lacunoso com várias camadas de células (Figuras $2 \mathrm{~A}, 2 \mathrm{~B}$ e $2 \mathrm{C}$ ), cavidades secretoras próximas à epiderme adaxial (Figuras 2A e 2D) e abaxial (Figuras 2A e 2E). Em algumas regiões nota-se parênquima paliçádico bisseriado (Figura 2I). Observam-se no parênquima paliçádico idioblastos contendo drusas (Figura 2G) e cristais prismáticos (Figura $2 \mathrm{H}$ ). Os feixes vasculares de menor calibre apresentam extensão de bainha e esclerênquima associado ao floema e xilema (Figura $2 \mathrm{~F}$ ).

Reações histoquímicas com o reagente de Steinmetz evidenciam além da cutícula espessa na epiderme adaxial, compostos fenólicos no parênquima paliçádico e lacunoso (Figura 2l). Compostos fenólicos são também evidenciados pelo cloreto férrico. Em reação com Sudan III, além da cutícula, observam-se gotas de material lipídico nos parênquimas paliçádico e lacunoso (Figura 2C)
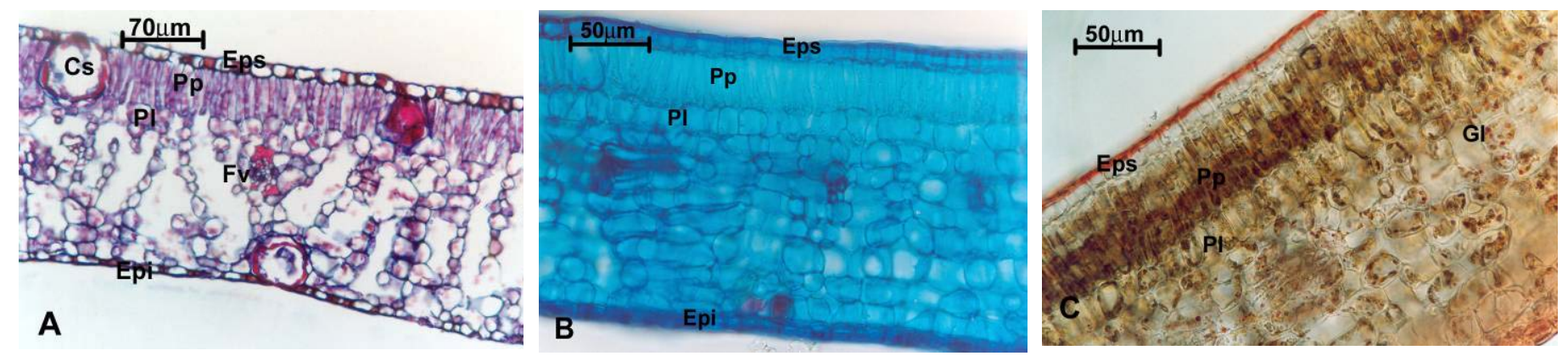
Fiuza, T. S. et al./Revista Eletrônica de Farmácia Vol 5(2), 21-31, 2008.
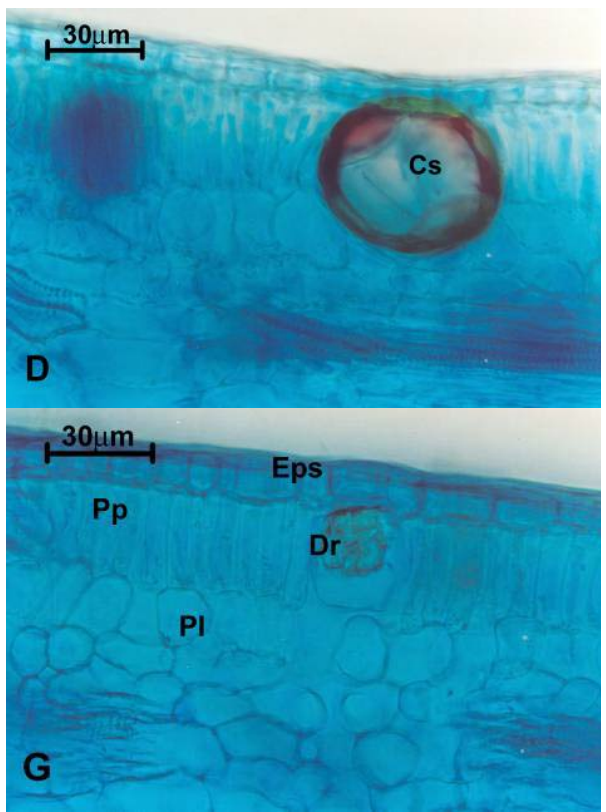
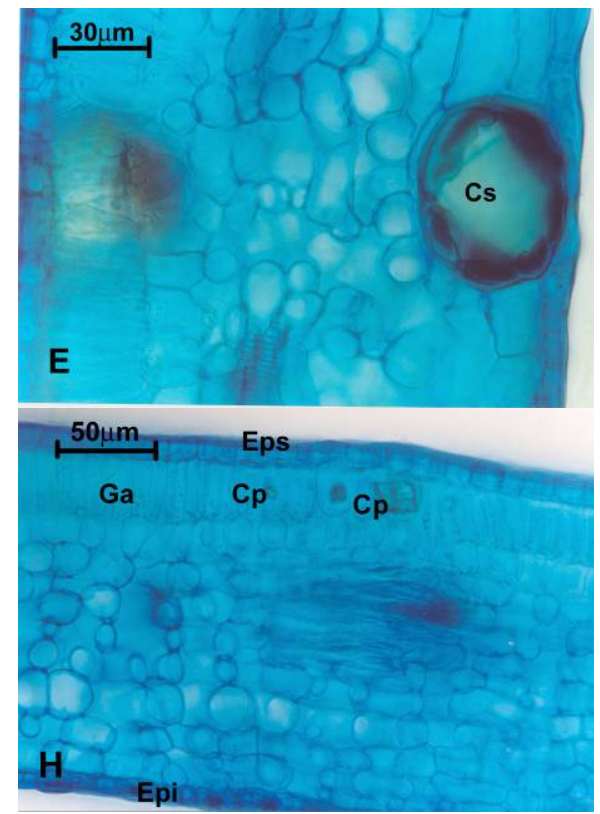
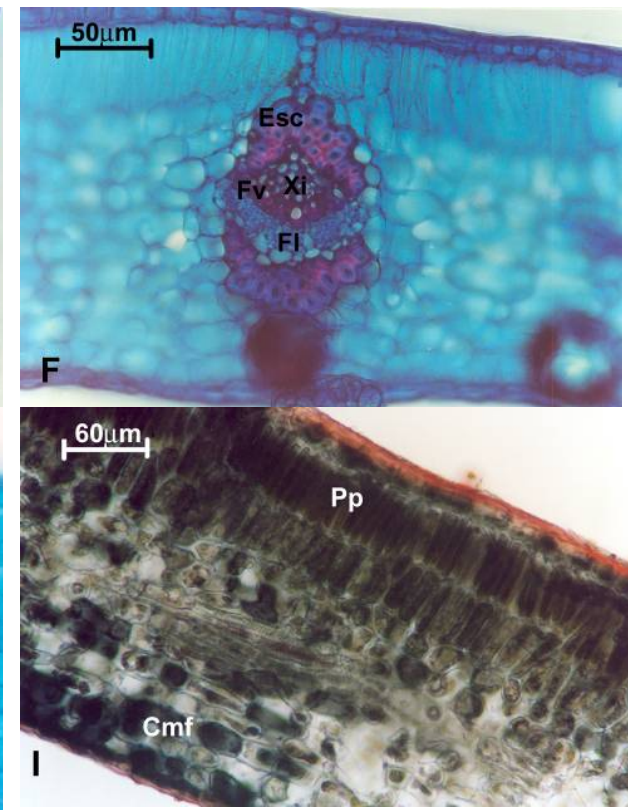

Figura 2. Secções transversais da lâmina foliar de Eugenia uniflora L. A - Secção transversal em preparação permanente. Aspecto geral. B - Aspecto geral do mesofilo. C - Cutícula espessa na epiderme adaxial e gotas lipídicas. D - Detalhe da cavidade secretora próxima à epiderme adaxial. E - Detalhe da cavidade secretora próxima à epiderme abaxial. F - Detalhe do feixe vascular com extensão de bainha. G - Detalhe de idioblasto contendo drusas no parênquima paliçádico. H - Detalhe de idioblasto contendo cristais prismáticos no parênquima paliçadico. I - Detalhe da cutícula e compostos fenólicos. A - Coloração Safrablau. B, D E, F, G e H - Coloração azul de Alcian/Safranina. C - Histoquímica com Sudan III. I = Histoquímica com reagente de Steinmetz. Cmf = célula com material fenólico; $\mathbf{C p}=$ cristais prismáticos; $\mathbf{C s}=$ cavidade secretora; $\mathbf{D r}=$ drusa; $\mathbf{E p i}=$ epiderme abaxial; Eps = epiderme adaxial; Esc = esclerênquima; FI = floema; Fv = feixe vascular; $\mathbf{G a}=$ grãos de amido; $\mathbf{G I}$ = gotas de material lipídico; $\mathbf{P I}=$ parênquima lacunoso; $\mathbf{P p}=$ parênquima paliçádico; $\mathbf{X i}=$ xilema.

Os bordos apresentam a mesma estrutura organizacional nas regiões apical, mediana e basal, com epiderme unisseriada e cutícula espessa (Figuras 3A, 3B e 3D). Sob a epiderme observa-se colênquima, apresentando idioblastos contendo drusas e cristais prismáticos (Figuras 3C e 3D). Nas proximidades da região colenquimática dos bordos, observa-se parênquima paliçádico (Figuras 3A, 3B, 3C e 3D) e parênquima lacunoso (Figuras 3A, 3B e 3D). Visualizam-se também cavidades secretoras próximas ao bordo, localizadas junto à epiderme adaxial e abaxial (Figuras 3B, 3C e 3D).
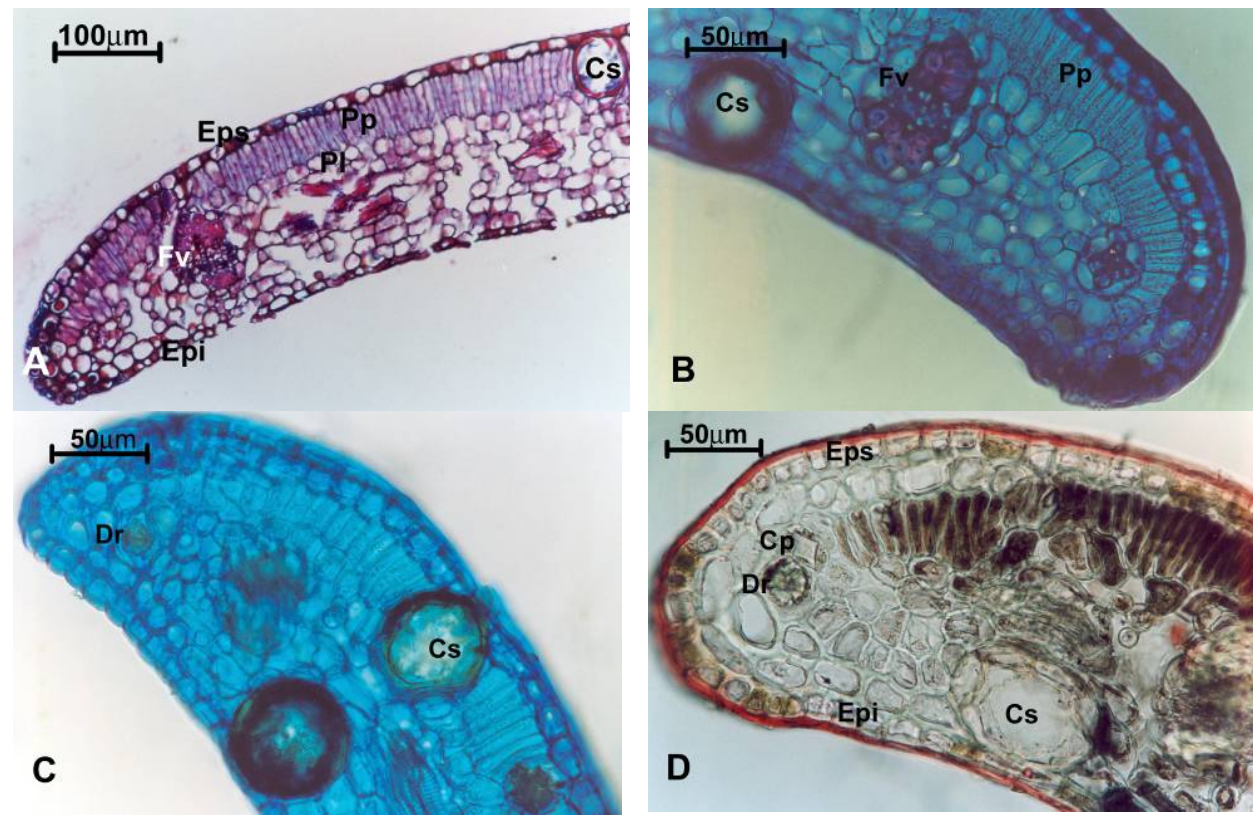

Figura 3. Secções transversais do bordo das folhas de Eugenia uniflora. A - Bordo da região mediana em preparação permanente submetida à coloração safrablau. B - Bordo da região mediana em coloração com azul de Alcian/Safranina, evidenciando feixes vasculares. C - Bordo da região basal em coloração com azul de 
Fiuza, T. S. et al./Revista Eletrônica de Farmácia Vol 5(2), 21-31, 2008.

Alcian/Safranina evidenciando drusas e cavidades secretoras. D - Bordo da região basal submetidas à histoquímica com reagente de Steinmetz evidenciando cutícula espessa. $\mathbf{C p}=$ cristal prismático; $\mathbf{C s}=$ cavidade secretora; $\mathbf{D r}=$ drusa; Epi = Epiderme abaxial; Eps = Epiderme adaxial; Fv = feixe vascular; Pp = parênquima paliçádico; PI = parênquima lacunoso.

A nervura principal de E. uniflora, em secção transversal, apresenta epiderme adaxial e abaxial unisseriada. O parênquima paliçádico unisseriado ocorre até as proximidades do sistema vascular (Figura 4A). Cavidades secretoras são identificadas próximas ao sistema vascular, em ambas as faces da lâmina foliar. Colênquima com até três camadas de células é registrado na face adaxial (Figuras 4B e 4D). Cristais prismáticos e em forma de drusa ocorrem no parênquima cortical. Cristais prismáticos também são observados no floema (Figuras 4B e 4C). O sistema vascular é bicolateral em forma de arco aberto, envolto por faixa esclerenquimática (Figuras 4A, 4B e 4C). Em reações de histoquímica com reagente de Steinmetz e Sudan III observa-se a presença de cutícula espessa tanto na epiderme abaxial quanto na adaxial.
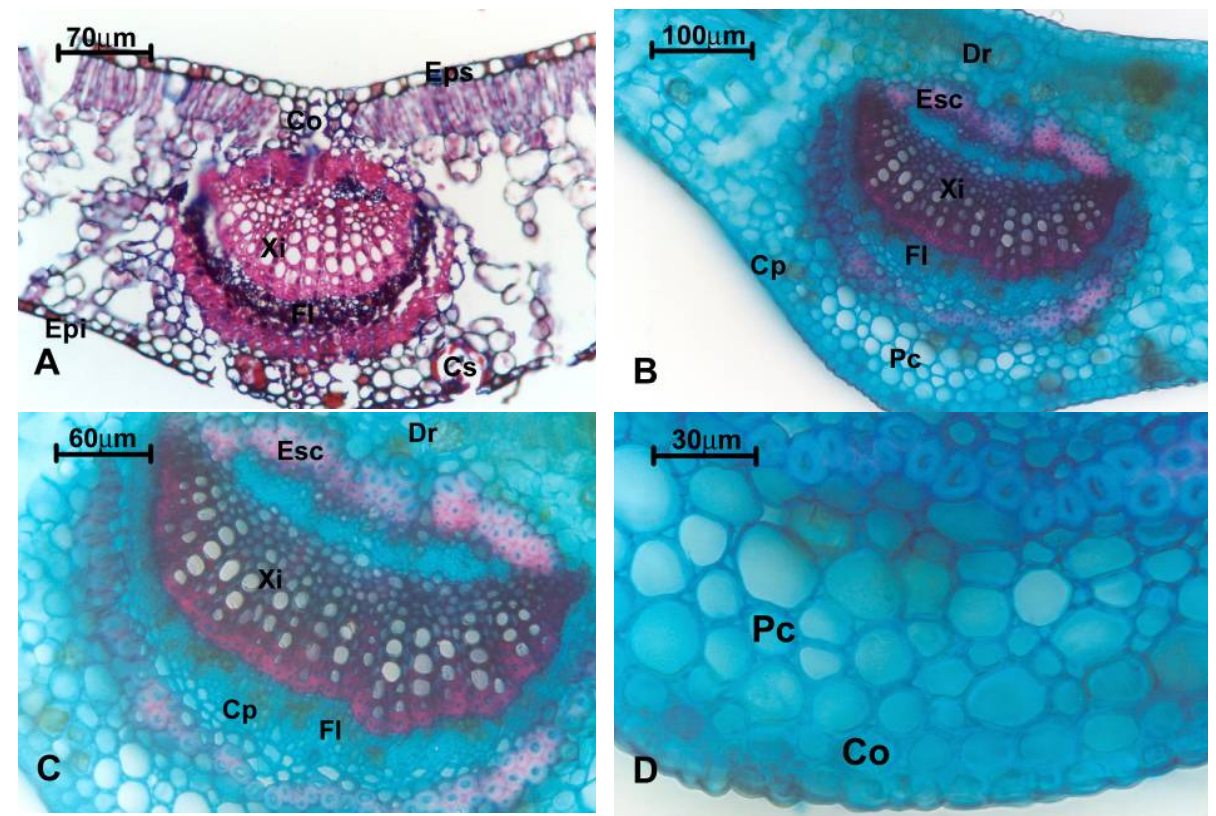

Figura 4. Secções transversais da nervura principal das folhas de Eugenia uniflora. A - Aspecto geral em lâmina permanente em coloração Safrablau. B - Aspecto geral em coloração de azul de Alcian/safranina. C - Detalhe do sistema vascular. D - Detalhe da epiderme abaxial. $\mathbf{C o}=$ colênquima; $\mathbf{C p}=$ cristal prismático; $\mathbf{C s}=$ cavidade secretora; $\mathbf{D r}=$ drusa; $\mathbf{E p i}=$ epiderme abaxial; $\mathbf{E p s}=$ epiderme adaxial; $\mathbf{E s c}=$ esclerênquima; $\mathbf{F I}=$ floema; $\mathbf{P c}=$ parênquima cortical; $\mathbf{X i}=$ xilema.

O pecíolo, em secção transversal, apresenta forma côncavo-convexa (Figura 5A), com epiderme unisseriada seguida de tecido colenquimático, cavidades secretoras e parênquima cortical contendo grande quantidade de cristais em forma de drusa (Figuras 5B, $5 \mathrm{C}$ e $5 \mathrm{E}$ ). O sistema vascular central é bicolateral, em forma de arco, envolvido por faixa esclerenquimática (Figuras 5A e 5B). Cristais prismáticos são observados no floema (Figuras 5B e 5D). Reações de histoquímica com reagente de Steinmetz evidenciaram a presença de cutícula espessa em toda a extensão da epiderme e células ricas em conteúdo fenólico (Figura 5F). 
Fiuza, T. S. et al./Revista Eletrônica de Farmácia Vol 5(2), 21-31, 2008.
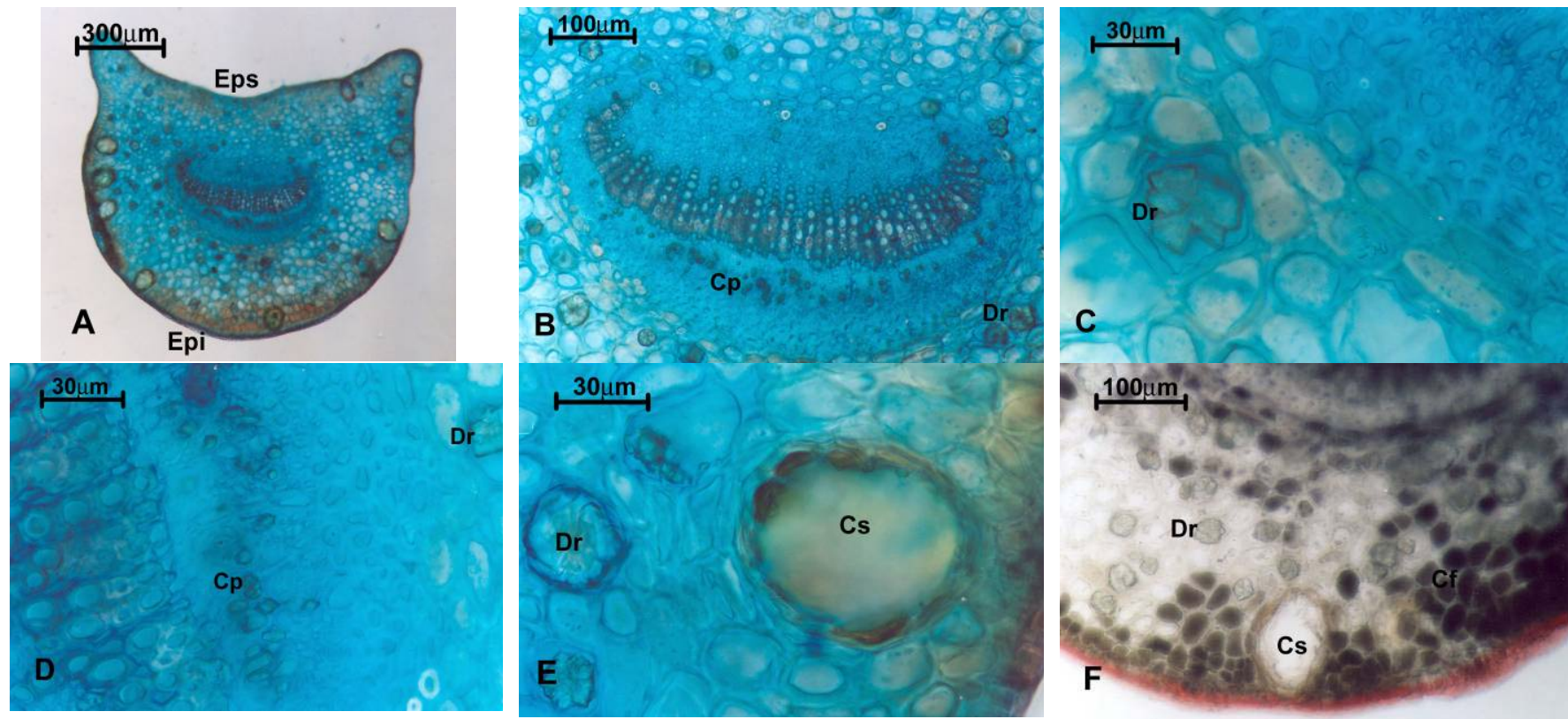

Figura 5. Secções transversais do pecíolo das folhas de Eugenia uniflora L. A - Aspecto geral. B - Detalhe do sistema vascular. C - Detalhe de drusa. D - Cristais prismáticos no floema. E - Detalhe da cavidade secretora. F Histoquímica com reagente de Steinmetz evidenciando cutícula espessa, cristais em forma de drusa, compostos fenólicos e cavidade secretora. $\mathbf{C f}=$ células com conteúdo fenólico; $\mathbf{C p}=$ cristais prismáticos; $\mathbf{C s}=$ cavidade secretora; $\mathbf{D r}=$ drusa; Epi = epiderme abaxial; $\mathbf{E p s}=$ epiderme adaxial.

O caule na região do segundo entrenó, em corte transversal, apresenta forma oval (Figura 6A), epiderme unisseriada (Figuras $6 \mathrm{~A} \mathrm{e} 6 \mathrm{C}$ ), colênquima com uma a duas camadas de células, parênquima cortical com células isodiamétricas de tamanhos variados, com presença de raros cristais em forma de drusas, endoderme contendo grãos de amido e cavidades secretoras próximas à epiderme. O felogênio se origina no periciclo, sendo que as células derivadas externas apresentam-se volumosas e alongadas no sentido anticlinal (Figuras 6B, 6D e 7A), diferenciando-se em súber. No cilindro vascular observa-se crescimento secundário. O sistema vascular apresenta floema localizado externamente e internamente ao xilema (Figuras 6A e 6D). Registram-se grãos de amido no parênquima floemático.
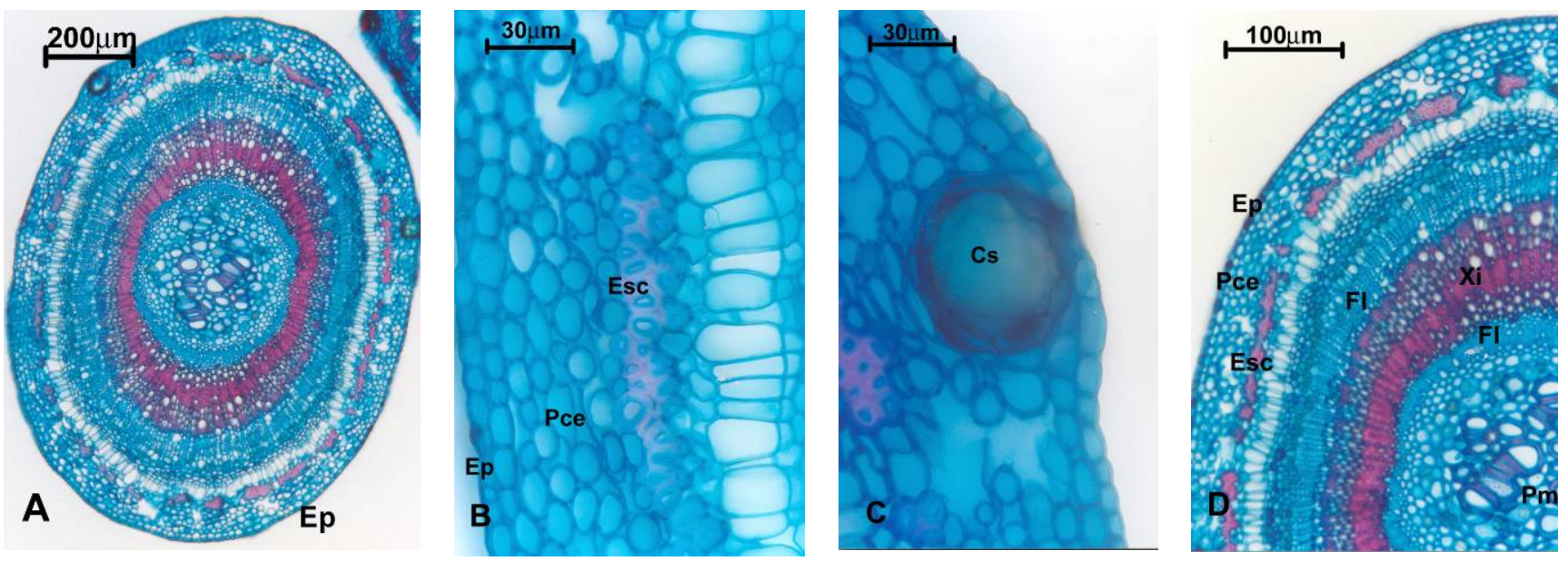

Figura 6. Secções transversais do caule na região do segundo entrenó de Eugenia uniflora L.. Coloração azul de Alcian/safranina. A - Aspecto geral. B - Detalhe da epiderme, parênquima cortical e esclerênquima. C - Detalhe da cavidade secretora próxima à epiderme. $\mathbf{D}$ - Aspecto geral do sistema vascular. $\mathbf{C s}=$ cavidade secretora; $\mathbf{E p}=$ epiderme; Esc = esclerênquima; $\mathbf{F I}$ = floema; $\mathbf{P c e}=$ parênquima cortical; $\mathbf{P m}=$ parênquima medular; $\mathbf{X i}=$ xilema .

No parênquima medular observa-se a presença de células com paredes lignificadas e com pontuações, drusas, cristais prismáticos (Figuras 7B e 7C) e grãos de amido. Presença de cristais prismáticos no floema formando uma bainha cristalífera. Histoquímica com Sudan III evidencia cutícula espessada na epiderme e com Steinmetz (Figura 7D) e cloreto férrico, conteúdo fenólico. 
Fiuza, T. S. et al./Revista Eletrônica de Farmácia Vol 5(2), 21-31, 2008.
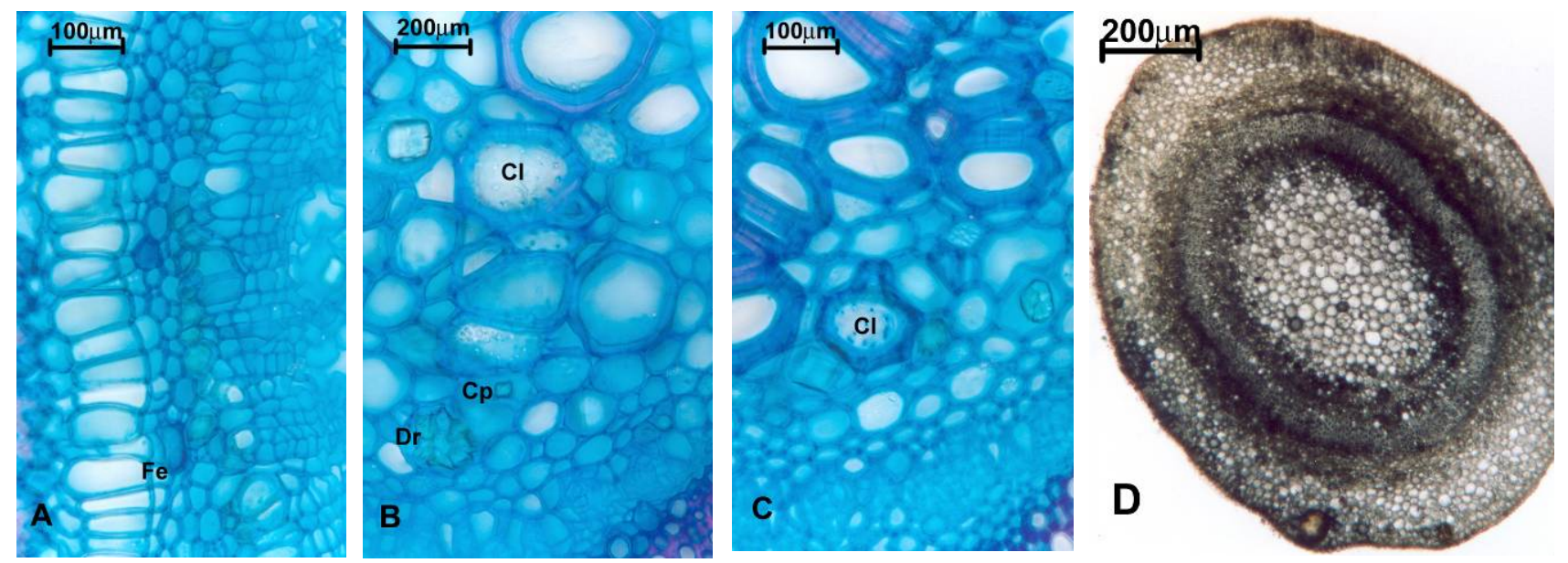

Figura 7. Secções transversais do caule na região do segundo entrenó em estrutura secundária de Eugenia uniflora L.. A - Detalhe do felogênio (Fe). B e C - Detalhe do parênquima medular mostrando drusas (Dr), cristais prismáticos (Cp) e células com paredes lignificadas e pontuações $(\mathbf{C l})$. D - Histoquímica com reagente de Steinmetz evidenciando material fenólico.

No pó das folhas, submetido ao reagente de Steinmetz, observam-se fragmentos de epiderme, mesofilo e elementos vasculares, cristais em forma de drusa e cristais prismáticos de formas variadas.

\section{Testes de pureza}

O pó das folhas de E. uniflora apresentou teor de cinzas totais de $11,49 \%$, cinzas insolúveis em ácido de $0,57 \%$ e teor de umidade de $8,93 \%$.

\section{Triagem fitoquímica}

Na triagem fitoquímica do pó das folhas de Eugenia uniflora, observou-se a presença de antraquinonas, esteróides, triterpenos, heterosídeos flavonóides, heterosídeos saponínicos e taninos. Não foram detectados alcalóides, amido, cumarinas e heterosídeos digitálicos.

\section{Obtenção do extrato etanólico, frações e perfil cromatográfico em CCD}

O rendimento do extrato etanólico bruto a partir do pó das folhas de $E$. uniflora foi de $25,78 \%$. O rendimento das frações a partir do extrato bruto foi de 13,8\% para a fração hexano, 11,7\% para a fração clorofórmio e $9 \%$ para a fração acetato de etila.

A fase móvel que melhor separou os componentes foi acetona/tolueno/ácido fórmico (3:3:1). A análise em CCD indicou a presença de flavonóides (Rfs próximos de 0,5$)$ e taninos ( $R f$ no terço superior) nas frações acetato de etila; flavonóides (Rfs próximos de 0,5 ) e terpenos (Rf no terço superior) na fração clorofórmio; e terpenos (Rf no terço superior) na fração hexano.

\section{Doseamento de fenóis totais, taninos e flavonóides}

O teor de fenóis totais da amostra do pó das folhas de $E$. uniflora foi de $9,22 \%$, o teor de taninos de 5,08 \% e a percentagem de flavonóides totais de $0,53 \%$.

\section{DISCUSSÃO}

A análise morfo-anatômica das folhas da E. uniflora realizada neste estudo, está de acordo com a descrição da E. uniflora encontrada na Farmacopéia Brasileira IV (2003) e revelou a presença de características gerais da família Myrtaceae como presença de folhas hipoestomáticas com estômatos anomocíticos, cavidades secretoras, drusas e cristais prismáticos (METCALF e CHALK, 1950). De acordo com Donato e Morretes (2007), o conteúdo das cavidades secretoras subepidérmicas no mesofilo das Myrtaceae é típico para cada espécie, sendo constituído por óleos essenciais. Os seus componentes químicos apresentam particularidades importantes para a farmacologia, além de serem importantes para a produção de essências. Estudos dos óleos voláteis da $E$. uniflora revelaram a presença de $\beta$-selineno, $\alpha$-selineno e nerolidol como componentes majoritários em folhas coletadas no Rio Grande do Sul, Brasil (HENRIQUES et al., 1993); selina-1,3,7(11)-trien-8-ona e oxidoselina-1,3,7(11)-trien8-one nas folhas coletadas Ceará, Brasil (MORAIS et al., 1996); limoneno, pulegona, carvona e nerolidol para espécies coletadas na Argentina (UBIERGO et al., 1987); furanodieno, selina-1,3,7(11)-trien-8-ona e oxidoselina1,3,7(11)-trien-8-ona nas folhas coletadas na Nigéria (WEYERSTAHL et al., 1988). 
Fiuza, T. S. et al./Revista Eletrônica de Farmácia Vol 5(2), 21-31, 2008.

Estudos anatômicos da E. uniflora realizados por Haron \& Moore, (1996) revelaram que as folhas apresentam uma superfície reticulada esculpida com tricomas estriados, estrias radiadas, finas e randomicamente orientadas. De acordo com Cardoso \& Sajo (2004) o padrão de nervação foliar da E. uniflora tende para o camptódromo-broquidódromo, onde as nervuras secundárias se anastomosam, desde a base da folha, e formam uma série de arcos próximos ao bordo. Soffiatti \& Alfonso (1999) descreveram que o lenho da E. uniflora apresenta vasos com distribuição difusa, placa de perfuração simples, pontuações intervasculares alternas e guarnecidas, traqueídes associadas aos vasos, e cristais abundantes. Parênquima axial difuso em agregados e formando linhas com uma a três células. Na casca, o floema caracteriza-se pela alternância de células vivas com células esclerificadas, as quais se distribuem em faixas. Há várias peridermes formando ritidoma; em cada periderme o súber é formado por uma, eventualmente duas camadas de células com diâmetro tangencial maior que o radial; a feloderme é formada por uma camada de células parenquimáticas, de paredes delgadas, com diâmetro radial maior que o tangencial; ocorrem eventualmente cristais no súber e na feloderme.

A triagem fitoquímica do pó das folhas de E. uniflora evidenciou a presença de heterosídeos antraquinônicos, esteróides, triterpenos, taninos, heterosídeos flavonóides e saponínicos. Flavonóides, taninos hidrolizáveis e condensados no pó das folhas de $E$. uniflora também foram descritos pela Farmacopéia Brasileira IV (2003). Panizza (1998) registrou nas folhas de E. uniflora, além de taninos e flavonóides, presença de saponinas e sais minerais e um pouco de vitamina C. Lee et al. (1997), investigando os constituintes fenólicos de folhas de $E$. uniflora, relataram a presença de eugeniflorina D1 $\left(\mathrm{C}_{75} \mathrm{H}_{52} \mathrm{O}_{48}\right)$ e eugeniflorina $\mathrm{D} 2\left(\mathrm{C}_{68} \mathrm{H}_{48} \mathrm{O}_{45}\right)$, além de dois taninos macrocíclicos hidrolisáveis, obtidos do extrato metanólico. De acordo com Simões et al. (2004) plantas ricas em taninos são empregadas na medicina tradicional no tratamento de diversas moléstias, tais como diarréia, hipertensão arterial, reumatismo, hemorragias, feridas, queimaduras, problemas estomacais (azia, náusea, gastrite e úlcera gástrica), problemas renais e do sistema urinário e processos inflamatórios em geral. As saponinas são componentes importantes para ação de muitas drogas vegetais, destacando-se aquelas tradicionalmente utilizadas como expectorantes e diuréticas. Plantas ricas em flavonóides são utilizadas para o tratamento de doenças circulatórias, hipertensão, como antivirais, anti-hemorrágicos, antiinflamatórios e antimicrobianos.

O teor de flavonóides encontrado no presente estudo foi inferior ao descrito pela Farmacopéia IV (2003) (mínimo de 2\%). Esta diferença no teor flavonóides pode ser devido a diferenças dos parâmetros climáticos e geográficos, como temperatura, altitude, pluviosidade, tipo de solo entre outros. O teor de taninos foi 5,08\%, entretanto, não há especificação para teor de taninos pelo método empregado neste estudo.

Os padrões de pureza da E. uniflora encontrados neste estudo (cinzas totais 11,49\%, cinzas insolúveis em ácido de $0,57 \%$ e teor de umidade de $8,93 \%$ ) estão de acordo com a monografia da Pitangueira descrita na Farmacopéia Brasileira IV (2003) que descreve que o teor de umidade tem que ser no máximo de 13\%, cinzas insolúveis no máximo de $2 \%$ e cinzas totais no máximo de $12 \%$.

O estudo morfo-anatômico das folhas da $E$. uniflora $L$ ampliou e aprofundou as informações contidas na Farmacopéia Brasileira IV (2003). A maior relevância deste trabalho foi a descrição anatômica do caule jovem, que não foi encontrada na literatura pesquisada. As características estruturais descritas neste trabalho, a prospecção fitoquímica e cromatográfica em camada delgada contribuem na identificação da espécie e fornecem parâmetros que poderão ser aplicados futuramente no controle de qualidade e no estudo farmacognóstico. A presença de heterosídeos antraquinônicos, esteróides, triterpenos, taninos, heterosídeos flavonóides e saponínicos podem justificar algumas atividades biológicas de uso popular desta planta.

\section{REFERÊNCIAS BIBLIOGRÁFICAS}

ALICE, C. B. et al. Screening of plants used in south Brazilian folk medicine. Journal of Ethnopharmacology. v.35, p.165-171, 1991.

ALONSO, J. R. Tratado de Fitomedicina. Bases Clínicas y Farmacológicas. Buenos Aires: Isis Ediciones S.R.L., 1998.

BANDONI, A. L. et al. Survey of Argentine medicinal plants. I. Folklore and phytochemical screening. Lloydia. v. 35, p. 69-80, 1972.

BUKASTSCH 1972 Bemerkungen zur doppelfärbung astrablausafranin.Mikrokosmos v.61, p. 255 apud KRAUS, J. E., ARDUIN, M. Manual básico de métodos em morfologia vegetal. Rio de Janeiro: EDUR. Editora Universidade Rural, 1997.

CARDOSO, C. M.; SAJO, M. G. Vascularização foliar e a identificação de espécies de Eugenia L. (Myrtaceae) da bacia hidrográfica do Rio Tibatgi, PR. Revista Brasileira de Boânicat. v. 27, n. 1, p. 47-54, 2004.

CONSOLINI, A. E.; BALDINI, O. A.; AMAT, A. G. Pharmacological basis for the empirical use of Eugenia uniflora L. (Myrtaceae) as antihypertensive. Journal of Ethnopharmacology. v. 66, p. 33-39, 1999. 
Fiuza, T. S. et al./Revista Eletrônica de Farmácia Vol 5(2), 21-31, 2008.

CONSOLINI, A. E.; SARUBBIO, M. G. Pharmacological effects of Eugenia uniflora (Myrtaceae) aqueous crude extract on rat' heart. Journal of Ethnopharmacology. v. 81, p. 57-63, 2002.

COSTA, A. F. Farmacognosia. Lisboa: Calouste Gulbenkian, 2001.

DONATO, A. M.; MORRETES, B. L. Anatomia foliar de Eugenia brasiliensis Lam. (Myrtaceae) proveniente de áreas de restinga e de floresta. Revista Brasileira de Farmacognosia. v.17, n. 3, p. 426-443, 2007.

FADEY, M. O.; AKPAN, U. E. Antibacterial activities of the leaf extracts of Eugenia uniflora Linn. (synonym, Stenocalyx michelii Linn.), Myrtaceae. Phytotherapy Research. v. 3, p. 154-155, 1989.

FARMACOPÉIA BRASILEIRA 4ª ed. Parte I. São Paulo: Editora Atheneu, 1988.

FARMACOPÉIA BRASILEIRA. 4ª ed. Parte II. Fasc. 5. São Paulo: Editora Atheneu, 2003.

FERRI, P. H. Química de Produtos Naturais: Métodos Gerais. In: DI STASI, L. C. Plantas Medicinais Arte e Ciências. Um Guia de Estudo Interdisciplinar. São Paulo: Editora Universidade Estadual Paulista, 1996.

HAGERMAN, A. E.; BUTLER, L. G. Protein precipitation method for the quantitative determination of tannins. Journal of Agricultural Food and Chemistry. v.26, p. 809-812. 1978.

HARON, N. W.; MOORE, D. M. The taxonimic significance of leaf micromorphology in the genus Eugenia L. (Myrtaceae). Botanical Journal of the Linnean Society. v.120, p. 265-277, 1996.

HENRIQUES, A. T. et al. Aromatic plants from Brazil II. The chemical composition of some Eugenia essential oils. Journal of Essential Oil Res. v.5, p.501-505, 1993.

HOLETZ, F. B. et al. Screening of some plants used in the Brazilian folk medicine for the treatment of infectious diseases. Memórias do Instituto Oswaldo Cruz. v. 97, n. 7, p.1027-1031, 2002.

JOHANSEN, 1940. Plant microtechnique. New York: McGraw-Hill Book, 1940.

KRAUS, J. E.; ARDUIN, M. Manual básico de métodos em morfologia vegetal. Rio de Janeiro: EDUR. Editora Universidade Rural, 1997.

LEE, M. I. et al. Two macrocyclic hydrolisable tannin dimers from Eugenia uniflora. Phytochemistry. v.44, p.13431349, 1997.

LORENZI, H.; MATOS, F. J. A. Plantas medicinais no Brasil nativas e exóticas. Nova Odessa, SP: Instituto Plantarum de Estudos da Flora Ltda, 2002.

METCALF, C. R.; CHALK, L. Anatomy of the Dicotyledons. Oxford: Science Publications, 1950.

MORAIS, S. M. et al. Volatile Constituents of Eugenia uniflora Leaf Oil from Northeastern Brazil. Journal of Essential Oil Res. v. 8, p. 449-451, 1996.

PANIZZA, S. Plantas que curam (Cheiro de Mato). $3^{\text {a }}$ edição. São Paulo: IBRASA, 1998.

PEPATO, M. T. et al. Lack of antidiabetic effect of a Eugenia jambolana leaf decoction on rat streptozotocin diabetes. Brazilian Journal of Medical and Biological Research. v.34, p. 389-395, 2001.

SANCHOTENE, M. C. C. Frutíferas nativas úteis à fauna na arborização urbana. Porto Alegre. Rio Grande do Sul: FEPLAM, 1985.

SASS, J. E. Botanical microtechnique. 3ed. lowa: State Press, 1951.

SCHAPOVAL, E. E. S. et al. Evaluation of some pharmacological activities on Eugenia uniflora L. Journal of Ethnopharmacology. v. 44, p. 137-142, 1994.

SCHMEDA-HIRSCHMAN, G. et al. Preliminary pharmacological studies on Eugenia uniflora leaves: xanthine oxidade inhibitory activity. Journal of Ethnopharmacology. v.21, p. 183-186, 1987. 
Fiuza, T. S. et al./Revista Eletrônica de Farmácia Vol 5(2), 21-31, 2008.

SIMÕES, C. M. O. et al. Farmacognosia da planta ao medicamento. $5^{\text {a }}$ edição. Porto Alegre, RS: Editora UFSC, 2004.

SOFFIATTI, P.; ALFONSO, V. A. Estudo anatômico comparativo do lenho e da casca de duas espécies de Eugenia L. (Myrtaceae). Revista Brasileira de. Botânica. v. 22, n. 2, p. 175-184, 1999.

UBIERGO, G.; TAHER, H. A.; TALENTI, E. C. Mono and sesquiterpenoids from the essential of Stenocalyx michelii. Anales Asociación Química Argentina. v. 75, p. 377-378, 1987.

WAGNER H, BLADT S. Plant Drug Analysis. A Thin Layer Chromatography Atlas. Second Edition. Berlim:Springer, 2001.

WEYERSTAHL, P. et al. Volatile constituents of Eugenia uniflora leaf oil. Planta Medica. v. 54, p. 546-549, 1988. 